\title{
Apoptosis in Various Organs of Preterm Infants: Histopathologic Study of Lung, Kidney, Liver, and Brain of Ventilated Infants
}

\author{
B. HARGITAI, V. SZABÓ, J. HAJDÚ, Á. HARMATH, M. PATAKI, P. FARID, Z. PAPP, B. SZENDE \\ First Institute of Pathology and Experimental Cancer Research, Semmelweis University Budapest, \\ Budapest, Üllõi út 26. H-1085 Hungary [B.H., V.S., P.F., B.S.]; First Department of Obstetrics and \\ Gynecology, Semmelweis University Budapest, Budapest, Baross u. 27. H-1085 Hungary [J.H., A.H., \\ Z.P.]; Second Department of Pediatrics, Semmelweis University Budapest, Budapest, Tûzoltó u. H-109 \\ Hungary [M.P.]
}

\section{ABSTRACT}

\begin{abstract}
Apoptosis, the well-characterized form of active programmed cell death, is a physiologic phenomenon in embryonal and fetal life in developing organs. Severe hypoxia, which occurs in most preterm infants, also leads to cell death, which may be necrotic or apoptotic. The aim of our study was to examine the incidence of apoptosis in various organs (such as lung, kidney, and brain) of preterm infants who suffered from clinically proven respiratory distress causing infantile respiratory distress syndrome (IRDS), cardiac failure, and periventricular leukomalacia (PVL). Twenty-four autopsy cases were studied histologically to detect the apoptotic ratio, which was performed on the basis of hematoxylin and eosin staining and validated by terminal deoxynucleotidyl transferase-mediated nick end-labeling (TUNEL) reaction. Elevated apoptotic ratio was found in stages II, III, and IV of bronchopulmonary dysplasia (BPD) among alveolar and bronchiolar cells. The apoptotic activity was very low in stage I of BPD. High apoptotic ratio was detected in hypoxic injuries of the
\end{abstract}

central nervous system (CNS) of preterm infants. Features of apoptosis were present in proximal and excreting tubules of the kidney. Significant elevation of apoptotic activity may play a role in the development of BPD, ischemic brain lesions, and renal failure. (Pediatr Res 50: 110-114, 2001)

Abbreviations
IRDS, infantile respiratory distress syndrom
TUNEL, terminal deoxynucleotidyl transfe
end-labeling
IVH, intraventricular hemorrhage
PVL, periventricular leukomalacia
CMV, cytomegalovirus
CNS, central nervous system
BPD, bronchopulmonary dysplasia
ARDS, adult respiratory distress syndrome

Apoptosis is the well-characterized form of active programmed cell death and plays an important role in organ development and cell differentiation. Various pathogenic effects occurring in preterm infants after assisted ventilation, such as severe hypoxia, oxygen toxicity, volutrauma/ barotrauma, sepsis, and lowered levels of antiproteases and antioxidant enzymes lead to cell death, which may also be apoptotic.

The aim of our study was to examine the incidence of apoptosis primarily in the lung and in selected cases in the liver, kidney, and brain of preterm infants who suffered clinically proven respiratory distress causing IRDS.

Received February 29, 2000; accepted August 18, 2000.

Temporary address for correspondence and reprints until September 2002: Beata Hargitai, M.D., Department of Paediatric Pathology, St. Michael's Hospital, University of Bristol, Southwell Street, Bristol BS2 8EG; e-mail: beatahargitai@hotmail.com. Permanent address: Beata Hargitai. M.D., Semmelweis University Budapest, First Institute of Pathology and Experimental Cancer Research, Budapest, Üllõi út 26. H-1085 Hungary; e-mail: BETTY@korb1.sote.hu
We hypothesized that this form of programmed cell death plays an important role in the development of BPD and other pathologic sequels of assisted ventilation and hypoxia, such as renal and hepatic failure, IVH, and PVL.

\section{METHODS}

Tissue samples were available from 24 preterm infants (24-36 wk gestation) who died of respiratory failure or IVH. All infants showed clinical and radiologic signs of IRDS, and hyaline membrane disease or BPD was proven by routine postmortem histologic examination. The lungs of two neonates, 27 and $36 \mathrm{wk}$ gestation, served as controls. These two infants died during labor with severe forms of diaphragmatic hernia. Histologic and TUNEL reactions showed that apoptosis of alveolar and bronchiolar cells was rare and the number of apoptotic figures in the brain, liver, and kidney was less than five per 10 microscopic fields ( $\times 20$ magnification). 
The tissue samples were obtained between 1993 and 1999 from autopsies at the First Institute of Pathology and Experimental Cancer Research of Semmelweis University of Medicine. The design of this study and methods, and the reported data have been approved by the Institutional Review Board.

Tissue blocks were fixed in 10\% phosphate-buffered formalin, dehydrated through graded ethanol, and embedded into paraffin. Five- $\mu$ m-thick sections were serially cut and mounted on Superfrost Plus (Menzel-Glaser, Freiburg, Germany) glass slides. The processed, sectioned, and deparaffinated tissues were stained with hematoxylin and eosin (Fig. 1).

Sections from the same blocks were prepared for evaluation of apoptosis by applying the TUNEL method (ApopDETEK Cell Death Assay System; Enzo, New York, U.S.A.). The incorporated deoxynucleotides were detected with a horseradish peroxidase-diaminobenzidine in situ detection system (Simply Sensitive Horseradish Peroxidase-DAB In Situ Detection System; Enzo, New York, U.S.A.).

The ratio of positively labeled pulmonary alveolar and bronchiolar epithelial cells, neural cells, renal tubular cells, and hepatocytes was determined microscopically. In the lungs and kidneys, apoptotic activity was considered marked $(++)$ if the ratio of TUNEL-positive cells exceeded $30 \%$ per terminal airway or per renal tubule. If this ratio was below $30 \%$, apoptosis was considered mild $(+)$; if no apoptotic cells were found it was negative (-). In liver and brain tissue, the number of TUNEL-positive cells was counted in 10 microscopic fields using a $\times 20$ objective. Apoptotic activity was considered marked $(++)$ if more than 10 cells were positive; 5-10 TUNEL-positive cells was considered mild activity.

\section{RESULTS}

Apoptosis in pulmonary tissue of preterm infants. Lung tissue of 24 preterm infants was examined retrospectively. The neonates were born in gestational wk 24-37, their birth weight was $600-2000 \mathrm{~g}$, and their age at death was $10 \mathrm{~h}-27 \mathrm{wk}$. All had clinically proven respiratory distress; ventilation, infection, and medication data are summarized in Table 1.

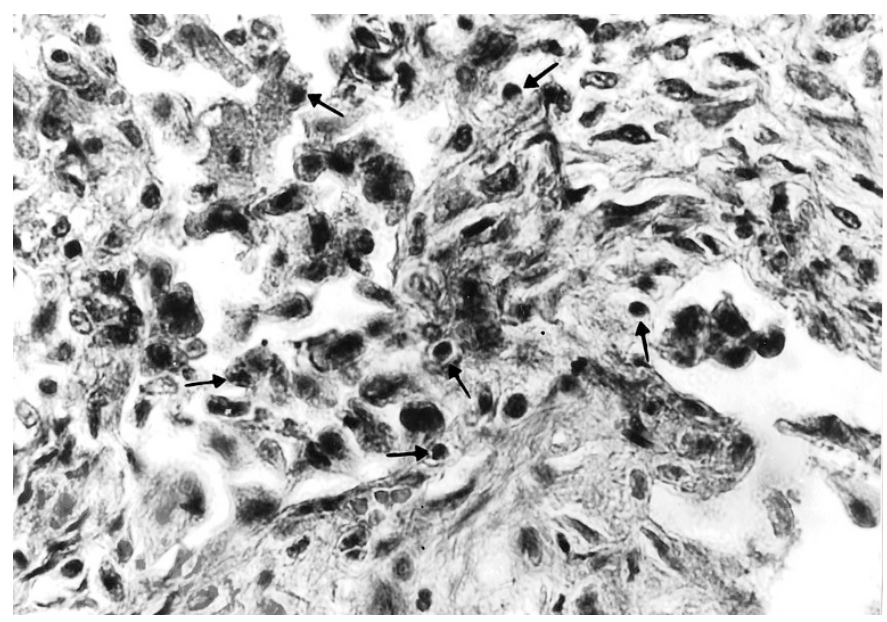

Figure 1. Hematoxylin- and eosin-stained lung tissue section from a preterm neonate with stage III of BPD. The characteristic signs of apoptosis in bronchiolar epithelial cells are well visible (HE, magnification $\times 300)$.
Marked apoptotic activity was found in nine cases, and apoptosis was present in another eight cases. In seven cases and in the control case this type of cell death could not be detected. The reaction was strong in pyknotic nuclei of dying cells, lining-expanded terminal sacculi, and in the injured bronchiolar epithelial cells (Fig. $2 A-C$ ). Cases with the most
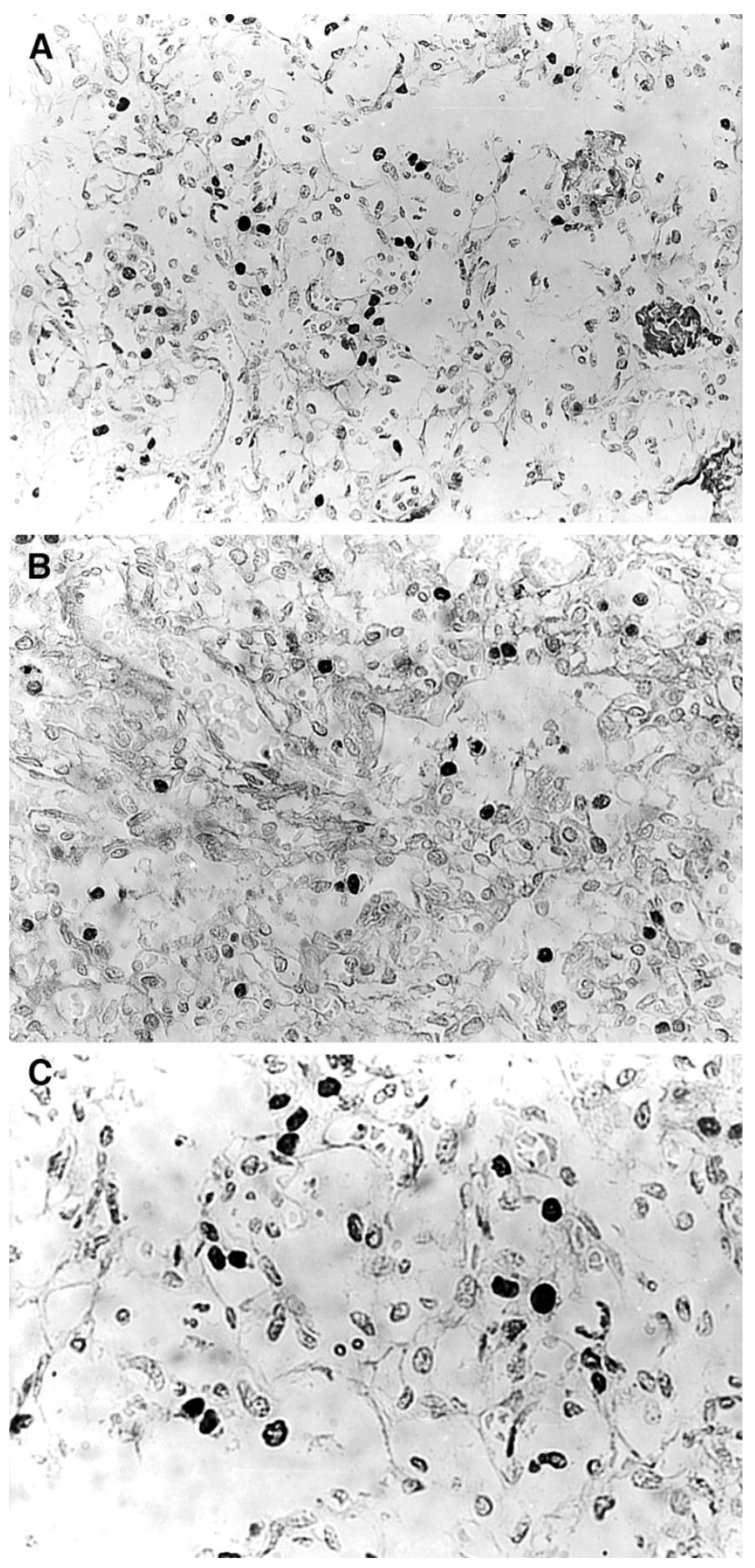

Figure 2. $A$, Marked apoptosis of bronchiolar and alveolar epithelial cells in the early subacute (second) phase of BPD (TUNEL immunoperoxidase, magnification $\times 150$ ). $B$ and $C$, Marked apoptosis of bronchiolar and alveolar epithelial cells in two cases of the late subacute stage of BPD. The ratio of TUNEL-positive cells exceeds $30 \%$ in the terminal airways (TUNEL immunoperoxidase, magnification $B \times 300 ; C \times 600$ ). 
Table 1. Apoptosis in lungs of artificially ventilated preterm infants

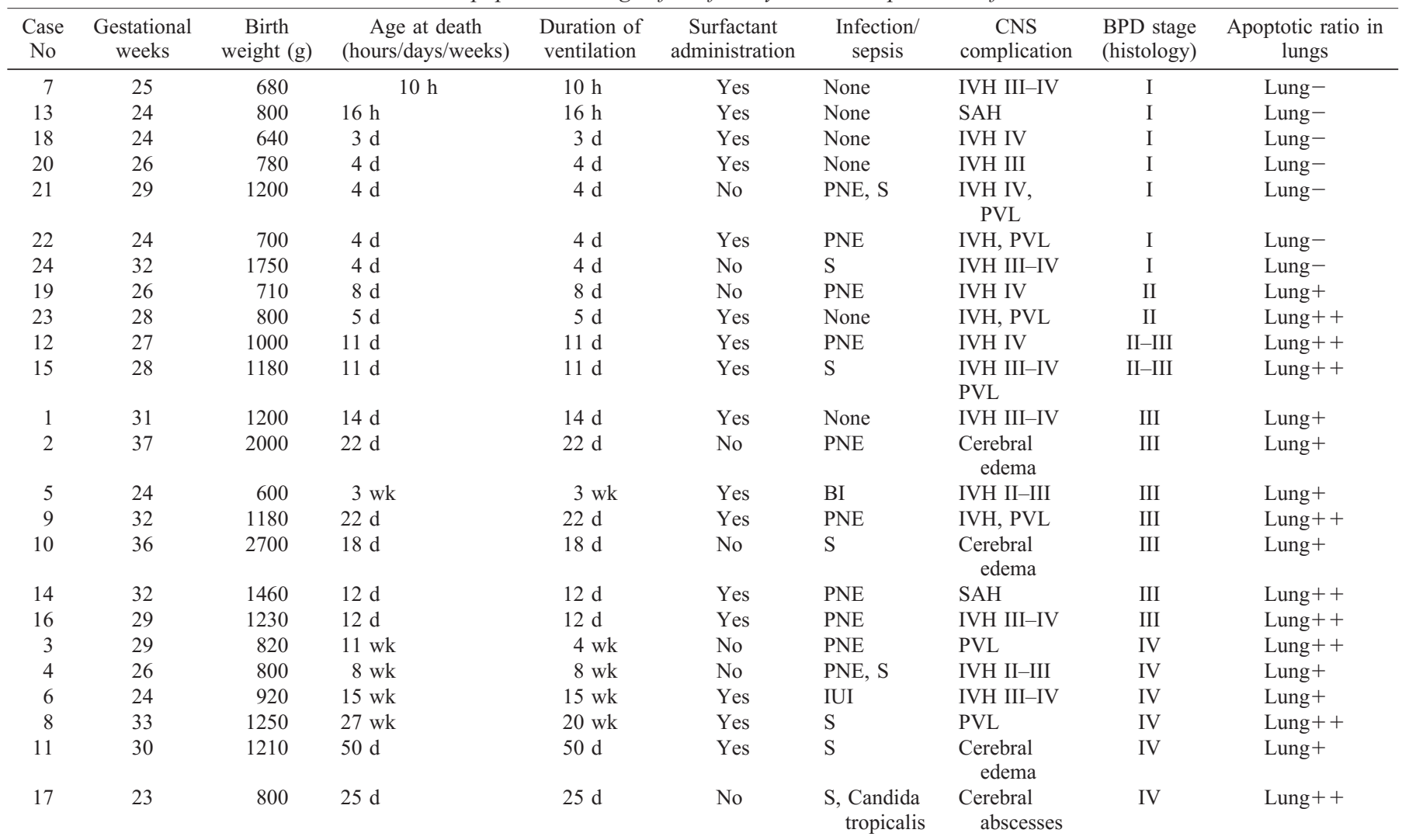

Abbreviations: PNE: bronchopneumonia; S: sepsis; BI: bacterial infection; IUI: intrauterine infection; IVH: intraventricular hemorrhage; PVL: periventricular leukomalacia; CNS: central nervous system; BPD: bronchopulmonary dysplasia; SAH: subarachnoidal hemorrhage.

$(++)$ : marked apoptotic activity.

$(+)$ : mild apoptotic activity.

$(-)$ : not elevated apoptotic activity.

Table 2. Apoptosis in brain of artificially ventilated preterm infants

\begin{tabular}{|c|c|c|c|c|c|c|c|c|}
\hline $\begin{array}{l}\text { Case } \\
\text { No }\end{array}$ & $\begin{array}{l}\text { Gestational } \\
\text { weeks }\end{array}$ & $\begin{array}{c}\text { Birth } \\
\text { weight }(\mathrm{g})\end{array}$ & $\begin{array}{c}\text { Age at death } \\
\text { (hours/days/weeks) }\end{array}$ & $\begin{array}{l}\text { Duration of } \\
\text { ventilation }\end{array}$ & $\begin{array}{c}\text { Surfactant } \\
\text { administration }\end{array}$ & $\begin{array}{l}\text { Infection/ } \\
\text { sepsis }\end{array}$ & $\begin{array}{c}\mathrm{CNS} \\
\text { complication } \\
\end{array}$ & $\begin{array}{c}\text { Apoptotic } \\
\text { ratio } \\
\end{array}$ \\
\hline 18 & 24 & 640 & $3 \mathrm{~d}$ & $3 \mathrm{~d}$ & Yes & None & IVH IV & Brain ++ \\
\hline 21 & 29 & 1200 & $4 d$ & $\mathrm{~N} 4 \mathrm{~d}$ & No & PNE, S & IVH IV, PVL & Brain+ \\
\hline 8 & 33 & 1250 & $27 \mathrm{wk}$ & $20 \mathrm{wk}$ & Yes & $\mathrm{S}$ & PVL & Brain ++ \\
\hline
\end{tabular}

Abbreviations: PNE: bronchopneumonia; S: sepsis; IVH: intraventricular hemorrhage; PVL: periventricular leukomalacia; CNS: central nervous system.

$(++)$ : marked apoptotic activity.

$(+)$ : mild apoptotic activity.

$(-)$ : not elevated apoptotic activity.

Table 3. Apoptosis in kidney and liver of artificially ventilated preterm infants

\begin{tabular}{|c|c|c|c|c|c|c|c|c|}
\hline $\begin{array}{l}\text { Case } \\
\text { No }\end{array}$ & $\begin{array}{l}\text { Gestational } \\
\text { weeks }\end{array}$ & $\begin{array}{c}\text { Birth } \\
\text { weight }(\mathrm{g})\end{array}$ & $\begin{array}{c}\text { Age at death } \\
\text { (hours/days/weeks) }\end{array}$ & $\begin{array}{l}\text { Duration of } \\
\text { ventilation }\end{array}$ & $\begin{array}{c}\text { Surfactant } \\
\text { administration }\end{array}$ & $\begin{array}{l}\text { Infection/ } \\
\text { sepsis }\end{array}$ & $\begin{array}{c}\text { Renal } \\
\text { dysfunction }\end{array}$ & Apoptotic ratio \\
\hline 18 & 24 & 640 & $3 \mathrm{~d}$ & $3 \mathrm{~d}$ & Yes & None & & Liver- kidney- \\
\hline 21 & 29 & 1200 & $4 \mathrm{~d}$ & $4 \mathrm{~d}$ & No & PNE, S & & Liver- kidney- \\
\hline 19 & 26 & 710 & $8 \mathrm{~d}$ & $8 \mathrm{~d}$ & No & PNE & & Kidney - \\
\hline 23 & 28 & 800 & $5 \mathrm{~d}$ & $5 \mathrm{~d}$ & Yes & None & & Kidney+ \\
\hline 2 & 37 & 2000 & $22 \mathrm{~d}$ & $22 \mathrm{~d}$ & No & PNE & & Kidney + liver ++ \\
\hline 9 & 32 & 1180 & $22 \mathrm{~d}$ & $22 \mathrm{~d}$ & Yes & PNE & & Brain ++ kidney + \\
\hline 8 & 33 & 1250 & $27 \mathrm{wk}$ & $20 \mathrm{wk}$ & Yes & $\mathrm{S}$ & & Kidney + brain ++ \\
\hline 11 & 30 & 1210 & $50 \mathrm{~d}$ & $50 \mathrm{~d}$ & Yes & S & & Liver- \\
\hline
\end{tabular}

Abbreviations: PNE: bronchopneumonia, S: sepsis.

$(++)$ : marked apoptotic activity.

$(+)$ : mild apoptotic activity.

$(-)$ : not elevated apoptotic activity. 
prominent activity were observed in stages II, III, and IV. The phenomenon was not seen in the acute-exudative stage of BPD. Apoptotic cells of mesenchymal origin, such as fibroblasts and macrophages in the interstitial, peribronchial, and perivascular connective tissue were present but not evaluated in this study.

Apoptosis in premature brain. In 16 of the 24 cases clinically diagnosed IVH occurred, and seven patients suffered from PVL.

Routine histologic examination was performed in four cases, three of which showed both IVH and PVL upon postmortem examination. Histologically, disorganization of the white matter and increased karyorrhexis were detected. A marked apoptotic activity (average 14.2; 15; 10.9 TUNEL-positive cells in 10 microscopic fields using a $\times 20$ objective) could be observed in damaged areas of the white matter and germinal layer in three cases, respectively (Fig. 3). In one case mild apoptotic activity was detected.

Apoptosis in the kidney and liver of preterm newborns. Kidney tissue was examined in seven cases and liver tissue in four cases. In case 8 hematuria was observed and CMV nephritis was diagnosed microscopically.

In one case marked apoptotic activity, and in four cases mild activity was detected with TUNEL reaction in the proximal and distal tubular epithelium. In two cases no apoptotic activity was observed in the kidneys.

In case 2 centrolobular fatty change was present in the liver. In the same areas prominent apoptotic activity (average 13.3 TUNEL-positive cells in 10 microscopic fields using $\times 20$ objective) was observed (Fig. 4). In three cases no apoptotic activity occurred in hepatocytes.

\section{DISCUSSION}

Severe complications of immaturity in preterm infants, such as pulmonary insufficiency or cerebral IVH, are the most common causes of death in this age group. Great advances in neonatal intensive care have improved survival and led to prolongation of life, but with an increased incidence of chronic respiratory difficulties, BPD, and disabilities of the CNS. These

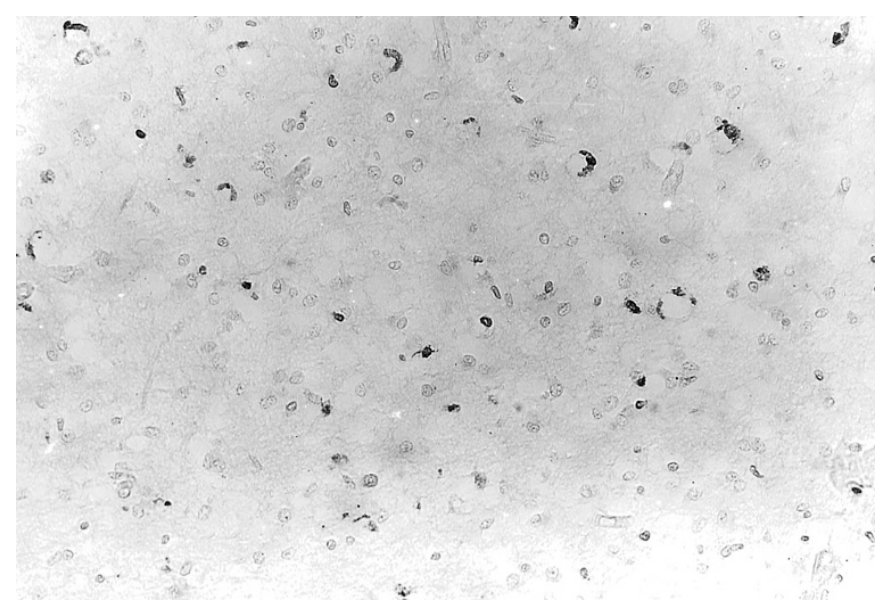

Figure 3. Brain tissue section of a ventilated preterm infant who suffered from PVL. In the damaged area of the white matter the TUNEL-positive cells represent high apoptotic activity (TUNEL immunoperoxidase, magnification $\times 600)$.

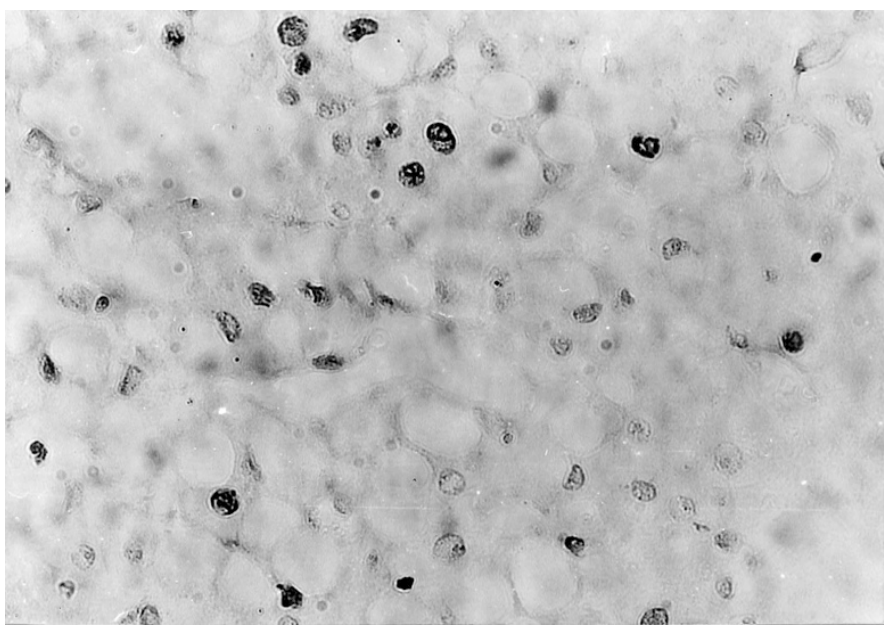

Figure 4. Fatty change in the liver of a ventilated preterm neonate. The nuclei of several hepatocytes show signs of apoptosis and are labeled positive with TUNEL reaction (TUNEL immunoperoxidase, magnification $\times 300$ ).

complications have both clinical and public health importance and are highly researched territories in pediatric science (1). In spite of this, much remains to study regarding the role of apoptosis in lung and CNS injuries of preterm newborns.

Data on the ontogeny, and the qualitative and quantitative changes in relation to the spatial and temporal occurrence of apoptosis in fetal and postnatal rat lung have previously been reported (2). Apoptosis in rat and human fetal lungs has been demonstrated as a normal feature of development (3). Antiapoptosis genes, such as survivin and bcl-2, are also present in human fetal tissue as the regulators of tissue differentiation and contribute to tissue homeostasis during fetal life (4).

Apoptosis is a major pathway in the destruction of type 2 pneumocytes in acute lung injury of adults with clinical symptoms of ARDS. In chronic interstitial pneumonia, however, type 2 pneumocytes show minimal apoptotic activity (5). Endothelial as well as epithelial cells show apoptosis, which plays a prominent role in lung remodeling after acute injury (6). Although apoptosis is prominent in the lungs of animals injured by inhaling $100 \% \mathrm{O}_{2}$, hyperoxia was proven to kill in vitro-cultured epithelial cells via necrosis, not apoptosis (7). Increased expression of stress proteins protects lung cells against endotoxin-mediated apoptosis and oxidant injury (8).

Our findings are supported by data from the literature, which emphasize the role of apoptosis in alveolar and bronchiolar epithelial cells in association with lung injury (5). The apoptotic activity of the epithelial cells is increased during the early and late subacute phases of lung remodeling and still exists in the chronic lung disease (stage IV of BPD). The possible causes of this process are multifactorial. The role of hypoxia, oxygen toxicity, steroid administration, lower level of superoxide dismutase, and the toxic effect of viral proteins in the development of programmed cell death are well known $(9,10)$. In addition, the role of other factors in association with the prophylaxis and treatment of BPD, such as volutrauma, surfactant administration, antenatal thyrotropin-releasing hormone administration, and permissive hypercapnia should also be considered in regard to apoptosis. 
The complications of prematurity and life-sustaining mechanical ventilation have not only pulmonary but neurologic consequences. Both hypocapnia and hypercapnia may alter neurodevelopmental outcomes, represented in the brain by severe periventricular echodensities, grade 3 or $4 \mathrm{IVH}$, or PVL (11). The presence of apoptotic phenomenon in the CNS has already been established. The role of hyperoxia and inhibition of glutathione synthesis was examined in an animal model, and increased nerve cell death via apoptosis was detected (12). Experimentally induced intrauterine infection in rabbits was described as the cause of fetal white matter lesions in which apoptosis was demonstrated (13). According to our preliminary results, apoptosis can be detected in white matter lesions of preterm neonates. In our case, with marked apoptotic activity of neural cells, clinically intrauterine infection with connatal pneumonia, well-developed BPD, and bacterial sepsis were diagnosed, which led to cerebral IVH and PVL. All of these, plus assisted ventilation, may be held responsible for the high apoptotic ratio in the brain lesions.

We also detected programmed cell death in the liver. The nuclei of several hepatocytes showed typical microscopic evidence of apoptosis. We could not find data in the literature about this phenomenon in the fetal liver.

Renal tubular damage may occur in preterm infants, causing electrolyte imbalance and poor growth $(14,15)$. Early stages of apoptosis, such as nuclear condensation, margination, and clumping of chromatin were observed in the nuclei of proximal and excreting tubules; these changes could be the structural background of renal tubular dysfunction.

\section{CONCLUSIONS}

The occurrence of apoptosis was examined in several organs of preterm neonates with acute and chronic lung disease (BPD). To the best of our knowledge this is the first report on the role of apoptosis in complications associated with prematurity.

We have shown this type of programmed cell death in type 2 pneumocytes in BPD and its importance in the disappearance of these cells during the late subacute stage of BPD. Apoptosis of mesenchymal cells was also detected in the chronic stage of BPD.

Our observations indicate that apoptosis in lesions of the CNS is a major mode of cell death. Apoptotic features seem to contribute to the evolution of neurodevelopmental deficits and cerebral palsy of preterm infants.

In the kidneys apoptosis was observed in tubular epithelial cells, but further data are needed to clarify the association with tubular dysfunction and intrinsic renal failure.

Our results suggest that apoptosis may play a prominent role in the pathogenesis of several diseases of premature infants, and further investigations will concentrate on the potential clinical applications of our findings.

\section{REFERENCES}

1. Barrington KJ, Finer NN 1998 Treatment of bronchopulmonary dysplasia. A review. Clin Perinatol 25:177-202

2. Kresch MJ, Christian C, Wu F, Hussai N 1998 Ontogeny of apoptosis during lung development. Pediatr Res 43:426-431

3. Scavo LM, Ertsey R, Chapin CJ, Allen L, Kitterman JA 1998 Apoptosis in the development of rat and human fetal lungs. Am J Respir Cell Mol Biol 18:21-31

4. Adida C, Crotty PL, McGrath J, Berrebi D, Diebold J, Altieri DC 1998 Developmentally regulated expression of the novel cancer anti-apoptosis gene survivin in human and mouse differentiation. Am J Pathol 152:43-49

5. Bardales RH, Su X, Schaefer RF, Su Ming H 1996 Apoptosis is a major pathway responsible for the resolution of type II pneumocytes in acute lung injury. Am J Pathol 149:845-852

6. Polunovsky VA, Chen B, Henke C, Snover D, Wendt D, Ingbar DH, Bitterman PB 1993 Role of mesenchymal cell death in lung remodelling after injury. J Clin Invest 92:388-397

7. Kazzaz J, Xu J, Palaia TA, Mantell L, Fein AM, Horovitz S 1996 Cellular oxygen toxicity. Oxidant injury without apoptosis. J Biol Chem 271:15182-15186

8. Wong HR, Wispe JR 1997 The stress response and the lung. Am J Physiol 273 (1 Pt 1):L1-9

9. Kaufmann SH 1997 Apoptosis Pharmacological Implications and Therapeutic Opportunities. Academic Press, London, pp 25-28, 258-265

10. Poirier J 1997 Apoptosis Techniques and Protocols. Humana Press Inc., Totowa, New Jersey, pp 219-221

11. Gannon CM, Wiswell TE, Spitzer AR 1998 Volutrauma, $\mathrm{PaCO}_{2}$ levels and neurodevelopmental sequelae following assisted ventilation. Clin Perinatol 25:159-175

12. Tagliatela G, Perez Polo JR, Rassin DK 1998 Induction of apoptosis during development by the combination of hyperoxia and inhibition of glutathione synthesis. Free Radic Biol Med 25:936-942

13. Yoon BH, Kim CJ, Romero R, Jun JK, Park KH, Chi JG 1977 Experimentally induced intrauterine infection causes fetal brain white matter lesions in rabbits. Am J Obstet Gynecol 177:797-802

14. Kojima T, Sasai Takedatsu M, Hirata Y, Kobayashi Y 1994 Characterisation of renal tubular damage in preterm infants with renal failure. Acta Pediatr Jpn 36:392-395

15. Guilerry EN 1997 Fetal and neonatal nephrology. Curr Opin Pediatr 9:148-153 